\title{
Pembinaan Peningkatan English Conversation Di Pantai Setokok Indah Setokok
}

\author{
Tomi Arianto \\ Universitas Putera Batam (UPB), Batam, Indonesia \\ e-mail: tomy2088.ta@gmail.com
}

\begin{abstract}
Setokok island beach is one of representative destinations in supporting the marine tourism area in Batam. The strategic location of Batam, which is close to neighboring Singapore and Malaysia, is a distinct advantage for this island, with many foreign tourists coming and going on vacation. The phenomena found that the coast guards and people around who should be directly involved in communicating with foreign visitors couldn't hardly communicate using English at all. The impact of that problem would narrow down the opportunity for coast guards to get additional benefits from this strategic situation. Therefore, the community team took the initiative to provide an English conversations training for coast guards, MSMEs, photographer services, managers, and people around the coast. The method taught was in the form of guidance and practice of English conversations according to the needs and conditions of the training participants. The materials given were in the form of greeting, directing, asking and answering questions, asking for clarification, offering, persuading, and daily vocabulary. The results obtained through community service at Pantai Setokok could be seen from the ability of the speaking conversation practice skills, the addition of vocabulary related to the beach, and the motivation of self-confidence using English.
\end{abstract}

Keywords: Batam Marine Tourism, Setokok Beach, English Conversation

\section{PENDAHULUAN}

Batam sebuah pulau yang terdapat di provinsi Kepulauan Riau, merupakan daerah yang menjadi destinasi paling strategis bagi pelancong luar negeri. Letak strategis Batam yang dekat dengan negara tetangga Singapura dan Malaysia menjadi keuntungan tersendiri bagi pulau ini yaitu dengan banyaknya wisatawan asing yang datang dan berlibur. Selain menjadi pusat industri, Batam akan dijadikan sebagai pintu utama bagi para wisatawan domestik dan manca negara untuk menikmati pariwisata di Indonesia. Sebagaimana dilansir dalam (tom, 2017), Jumaga Nadeak, ketua panitia khusus (Pansus) Rencana Induk Pengembangan Pariwisata Daerah (Rippda) menginformasikan bahwa Pansus akan merekomendasi Batam sebagai miniature windows of Indonesia atau jendela miniatur Indonesia. Mengonsepkan Batam sebagai miniatur Indonesia dimaksudkan untuk menarik sebanyak mungkin wisatawan terutama wisatawan asing berkunjung ke Batam dan destinasi wisata lainnya di Kepri ini (Anwar, 2016).

Pemerintah kota Batam (Suwanda, 2016) telah mendapatkan penghargaan pariwisata kategori indeks pariwisata tertinggi di Indonesia. Sektor pariwisata yang sehat dapat mendukung pertumbuhan ekonomi daerah maupun nasional. Seperti yang dipaparkan M. Rudi selaku walikota Batam di Jakarta (Suwanda, 2016) Batam merupakan kota dengan kunjungan wisatawan 
terbanyak setelah Bali dan Jakarta. Menurut data BPS November 2017, jumlah kunjungan wisatawan mancanegara yang datang ke Batam mencapai 10,6 juta orang dan semakin lama semakin meningkat (BPS, 2017). Keberhasilan pariwisata di Batam tidak lepas dari peran serta semua pemangku kepentingan seperti akademisi, pelaku bisnis, komunitas, pemerintah, dan media.

Wisata pantai termasuk pada kegiatan wisata bahari atau wisata kelautan. Adapun yang dimaksud dengan pantai wisata bahari adalah wisata yang objek dan daya tariknya bersumber dari potensi bentang laut (seascope) maupun bentang darat pantai (coastal landscape). Menurut Fandeli (2002) wisata bahari adalah wisata yang berupa kegiatan berenang, snorkeling, menyelam, berlayar, memancing, berjemur, rekreasi pantai, fisiografi, dan lain-lain. Hal ini sejalan dengan yang di sampaikan oleh Modjo dalam bukunya Membangun Wisata Desa mengatakan pariwisata menunjang pertumbuhan ekonomi rakyat, sebagaimana dipahami bahwa ada korelasi yang signifikan antara interaksi manusia dengan peningkatan ekonominya, artinya makin banyak manusia melakukan interaksi pada suatu lokasi membawa dampak konsekuensi peningkatan ekonomi yang optimal pula. Apabila wisatawan mendatangi suatu lokasi dengan tujuan berwisata maka mau tidak mau mereka akan mengeluarkan pembiayaan di dearah wisatawan tersebut (Modjo, 2012).

Pantai pulau Setokok merupakan satu dari destinasi yang bisa dikategorikan sebagai wisata bahari yang sering dikunjungi oleh wisatawan asing di Batam. Lokasi yang berdekatan dengan jembatan Barelang, salah satu ikon kota Batam, menjadikan pantai ini wajib dikunjungi, baik oleh wisatawan lokal maupun wisatawan mancanegara. Memiliki ciri khas pasir putih dan lingkungan yang asri, dilengkapi dengan fasilitas berenang, memancing, bermain, serta pemandangan yang hijau membuat pantai setokok banyak diminati pengunjung. Banyak pelaku yang terlibat secara langsung terhadap wisatawan asing yang berkunjung ke pantai setokok ini seperti; penjaga pantai (guide), petugas pantai (cleaning service, security, dll), pelaku Usaha mikro kecil menengah (UMKM), Jasa fotografer, pengelola pantai, serta masyarakat sekitar. Tentu saja bahasa inggris sebagai bahasa komunikasi internasional sangat dibutuhkan bagi para pelaku yang ada di pantai setokok tersebut.

Dari hasil wawancara yang dilakukan penulis ke lokasi, sangat disayangkan sekali hampir tidak ada penjaga pantai, petugas, pelaku UMKM dan masyarakat disekitar pantai setokok yang mampu berkomunikasi dengan menggunakan bahasa inggris. Ketika wisatawan mancanegara datang berkunjung, masyarakat dan penjaga pantai hanya menggunakan bahasa isyarat atau tidak berkomunikasi sama sekali. Tentu saja hal ini berdampak pada semakin berkurangnya peluang ekonomis yang mereka dapatkan dan meninggalkan kesan yang tidak nyaman dan memuaskan bagi pengunjung asing yang datang kesana.

Berdasarkan permasalahan yang dihadapi oleh penjaga pantai, pelaku UMKM, dan mayarakat disekitar pantai setokok, maka tim pengabdi masyarakat memberikan pelatihan bahasa inggris khususnya pada kemampuan berkomunikasi (Speaking English Skill). Hal ini dilakukan agar penjaga pantai dapat memberikan guiding yang baik, petugas pantai bisa memberikan instruksi dan petunjuk dengan lancar, pelaku UMKM dapat menawarkan produk belanjaannya, jasa fotografer dapat menawarkan jasanya, serta masyarakat 
sekitar juga dapat berkomunikasi dengan menggunakan bahasa inggris yang baik terhadap wisatawan mancanegara yang berkunjung di pulau Setokok.

\subsection{Waktu dan Tempat Pelaksanaan}

\section{METODE}

Kegiatan pengabdian kepada masyarakat ini dilakukan secara bertahap mulai tanggal 1, 8, dan 11 Febuari 2018 yang terbagi menjadi 3 pertemuan di tempat yang berbeda seperti yang dijelaskan pada tabel berikut ini;

Tabel 1 Waktu dan Tempat Pelaksanaan

\begin{tabular}{lccll}
\hline No & Tanggal & Waktu & \multicolumn{1}{c}{$\begin{array}{c}\text { Tempat } \\
\text { pelaksanaan }\end{array}$} & Kegiatan \\
\hline $\mathbf{1}$ & 1 Febuari 2018 & $15.00-17.00$ & $\begin{array}{l}\text { Gazebo } \\
\text { pulau Setokok }\end{array}$ & $\begin{array}{l}\text { Pantainan English } \\
\text { Conversation }\end{array}$ \\
$\mathbf{2}$ & 8 Febuari 2018 & $15.00-17.00$ & $\begin{array}{l}\text { Gazebo pantai pulau } \\
\text { setokok }\end{array}$ & $\begin{array}{l}\text { Pelatihan English } \\
\text { Conversation (in- } \\
\text { pair group) } \\
\text { One-to-one } \\
\text { conversation } \\
\text { training }\end{array}$ \\
\hline
\end{tabular}

Untuk lebih jelasnya lokasi pengabdian yang dilaksanakan di Pantai Pulau Setokok dapat dilihat pada peta dan gambar di bawah ini;

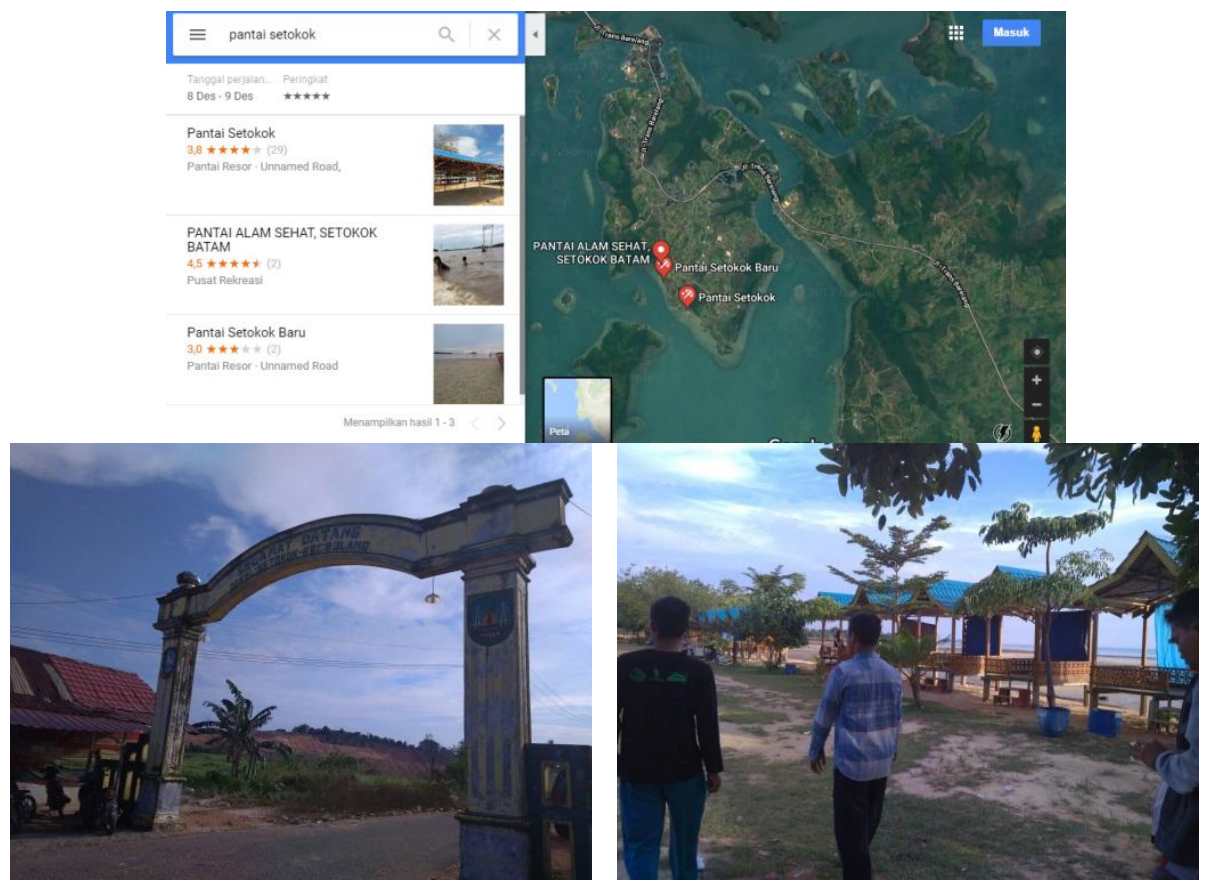

Gambar 1 Lokasi kegiatan

\subsection{Metode Pelaksanaan}


Metode yang dilakukan untuk menyelesaikan permasalahan oleh tim pengabdi adalah;

1. Melaksanakan wawancara (in-depth interview) untuk mengetahui karakteristik penjaga pantai dan masyarakat yang terlibat di lingkungan pantai pulau setokok.

2. Memberikan pretest kepada calon pembelajar berbentuk tanya-jawab sederhana dalam bahasa Inggris untuk mengetahui kemampuan berbahasa Inggris

3. Melaksanakan pelatihan dengan memberikan contoh-contoh percakapan seperti greeting, giving direction, asking and answering questions, asking for clarification, offering, and persuading serta kosakata bahasa Inggris (vocabulary) dengan teknik sesuai kebutuhan masing-masing.

4. Memberikan contoh-contoh percakapan berbahasa Inggris antara penjaga pantai dan pengunjung melalu slides dan memberi kesempatan untuk berlatih dalam kelompok (in-pair group)

5. Melakukan praktik langsung di lokasi pantai antara penjaga pantai, pelaku UMKM, fotografer, masyarakat dan pengunjung pantai (posttest).

6. Memberi masukan kelebihan dan kekurangan berbahasa Inggris hasil dari posttest (refleksi)

\section{HASIL DAN PEMBAHASAN}

\subsection{Hasil Pengabdian}

Pembinaan Peningkatan English Conversation dalam rangka Pembinaan Sasaran Pemberdayaan Masyarakat terhadap penjaga objek wisata pantai setokok disambut baik dan penuh antusias oleh para peserta pengabdian. Kegiatan yang dilaksanakan selama tiga hari tersebut diikuti dengan seksama dari awal hingga akhir pelatihan. Para peserta juga melibatkan anak muda untuk mengikuti kegiatan ini karena mereka banyak berinteraksi dengan wisatawan asing dan juga terlibat sehari-hari dalam kegiatan pantai. Kegiatan pembinaan peningkatan kemampuan bahasa inggris ini dilaksanakan di sekitar pantai setokok dan balai pertemuan masyarakat.

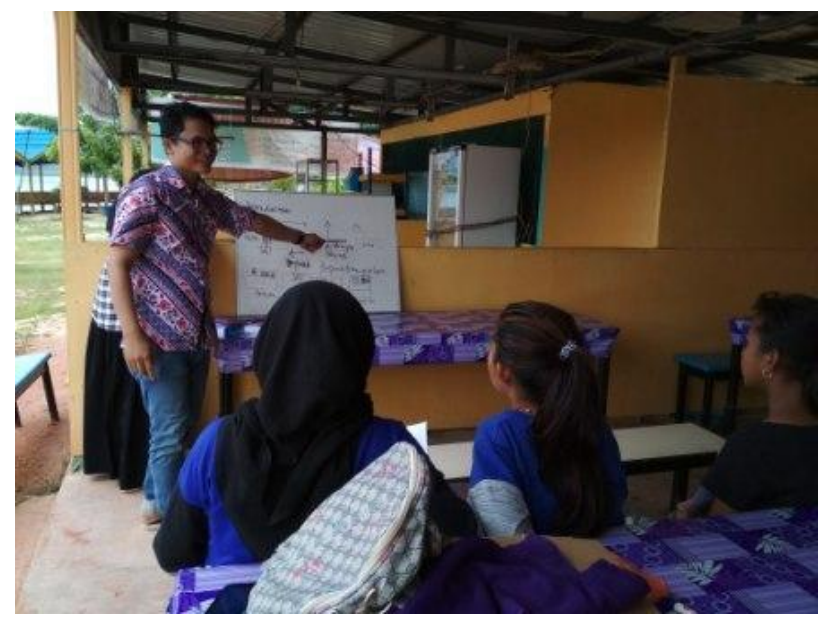

Gambar 2 Pertemuan pertama pembinaan peningkatan English conversation

Pada pertemuan hari pertama, tim pengabdi masyarakat memperkenalkan rencana pembinaan yang akan dilaksanakan selama tiga hari. Sebelum memulai 
pembelajaran, tim melakukan diskusi singkat untuk mengetahui sejauh mana kemampuan peserta dalam menggunakan bahasa inggris. Seperti informasi yang sebelumnya didapatkan, kemampuan bahasa inggris peserta pembinaan sangat kurang. Kosakata yang mereka miliki sangat terbatas. Beberapa anak muda telah mendapatkan pembelajaran bahasa inggris di sekolah namun kepecayaan diri untuk mempraktekan percakapan masih sangat kurang. Selanjutnya, tim pengabdian memberikan pelatih pertama mengenai percakapan dengan tema greeting (sapaan), introducting (memperkenalkan diri), dan giving direction (memberikan petunjuk arah) kepada para peserta. Pelatihan ditutup dengan praktek singkat oleh beberapa peserta secara tekstual.

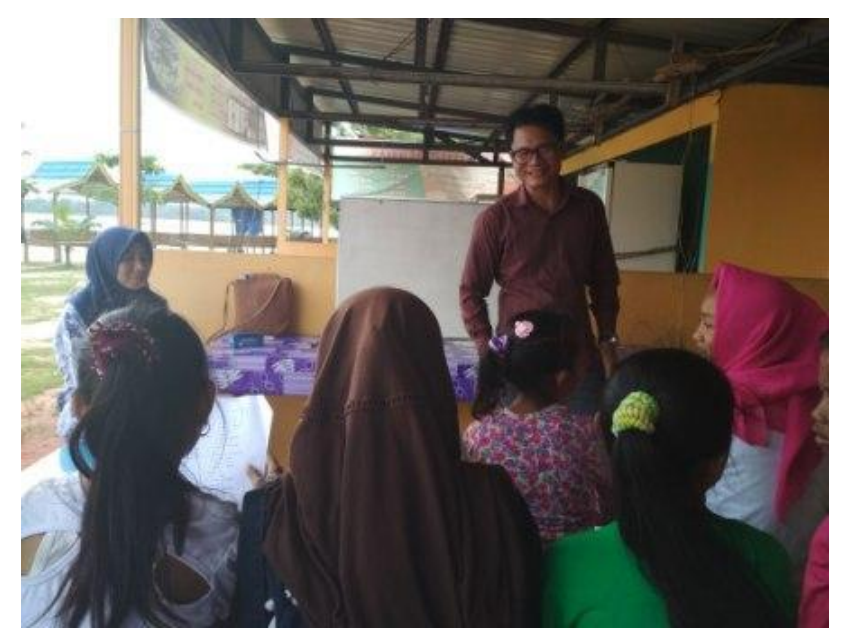

Gambar 3 Pertemuan kedua pembinaan conversation lanjutan

Pertemuan kedua dan ketiga, tim pengabdi melanjutkan pembinaan dengan memberikan teori dan dilanjutkan dengan simulasi praktek percakapan secara kelompok dan individu. Materi yang diajarkan dipertemuan ini berupa dengan memberikan contoh-contoh percakapan seperti greeting, giving direction, asking and answering questions, asking for clarification, offering, and persuading. Tim pengabdi juga memberikan kosakata yang berkaitan dengan pantai bagi peserta untuk selanjutnya bisa dihafal diluar pertemuan pengabdian. Peserta juga diminta untuk mempraktekan secara berkelompok dengan pasangannya secara tekstual dan non-tekstual. Tim pengabdi juga menggunakan alat bantu berupa papan tulis dan kertas materi agar peserta lebih fokus dan terarah mengikuti pelatihan.

Hasil dari pelatiahan ini dapat dilihat dari simulasi percakapan salah satu perserta penjaga pantai dalam menggunakan bahasa inggris. Peserta mulai bisa memberikan kalimat sapaan, memberikan arah, dan informasi sikat pantai. Peserta juga telah dibekali 98 kosakata terkait dengan pantai yang bisa terus dipraktekan dihari-hari sekitar pantai. Penguasaan percakapan bahasa inggris harus selalu dipraktekan agar apa yang telah diajarkan tetap melekat dan semakin biasa digunakan. Motivasi selalu disampaikan oleh tim pengabdi kepada masyarakat agar peserta tidak segan mempraktekan bahasa inggris kepada wistawan mancanegara yang datang ke pantai setokok.

\subsection{Pembahasan}


Objek wisata pantai sitokok merupakan satu destinasi yang banyak dikunjungi oleh wisatawan mancanegara. Penjaga pantai merupakan oang yang berinteraksi langsung dengan para pengunjung. Kemampuan berkomunikasi menggunakan bahasa inggris sangat diperlukan dalam menjaga stabilitas pengunjung ke objek pantai tersebut. Selain itu, Pengunjung bisa memanfaatkan penawaran jasa lainnya jika berani berkomunikasi bahasa inggris kepada pengunjung yang datang. Di pantai setokok sendiri ada banyak fasilitas jasa yang bisa dijajakan seperti fasilitas bermain air dengan kayaking, menaiki perahu sampan, berenang menggunakan benen, tempat bersantai di pondok dan hall, ruang pertemuan dan acara resepsi, makanan, hiburan, bahkan fasilitas toilet dan kamar mandi.

Kemampuan bahasa inggris yang kurang dimiliki oleh penjaga pantai menjadi keluhan sendiri bagi peserta. Pada hari pertama melakukan pelatihan, peserta hampir tidak memahami bagaimana memperkenalkan diri atau menyapa pengunjung wisatawan yang datang. Banyak dari peserta yang mengeluh karena tidak berani menyapa turis mancanegara. Para pelayan pantai rata-rata memiliki pendidikan rendah, sebagian ada yang kehilangan pekerjaan karena di PHK dari perusahaan. Kehadiran tim pengabdi memberikan harapan baru bagi penjaga pantai untuk dapat menambah kemampuannya berbahasa inggris. Sebagian mereka juga membawa anggota keluarganya atau anaknya untuk mengikuti pembinaan. Anak mereka juga sering dilibatkan dalam aktifitas pantai seperti melayani pengunjung di foodcourt, atau menjajakan makanan.

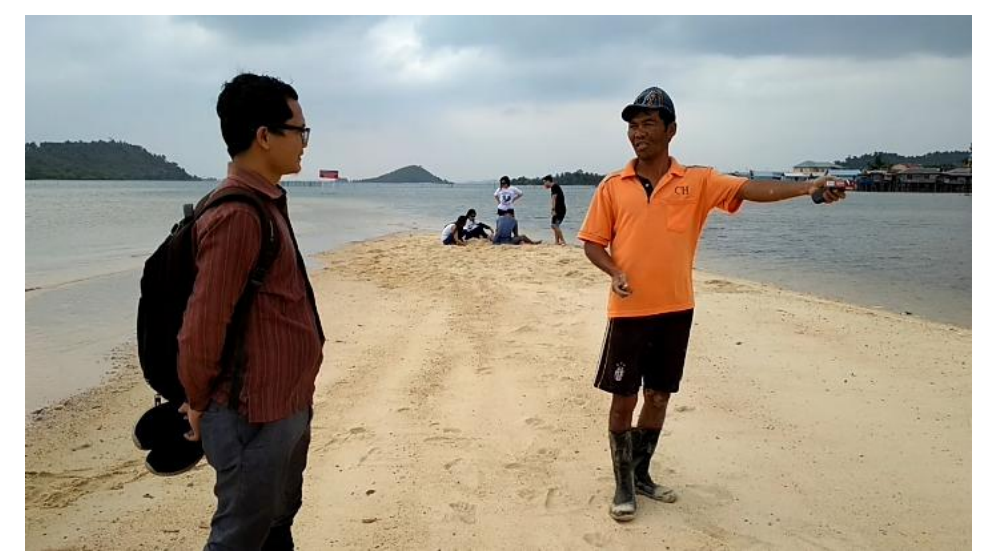

Gambar 4 Salah satu penjaga pantai setokok yang mempraktekan converation tentang greeting dan giving direction

Selama proses pembinaan, peserta mengikuti pelatihan dengan hikmat. Meski peserta awalnya ragu-ragu mempraktekan secara langsung usai pemberian materi. Namun peserta tetap memberikan kesan positif selama pembelajaran. Peserta juga tidak ragu untuk bertanya mengenai kosakata baru yang ia temui sehari-hari. Beberapa peserta juga menanyakan keraguannya untuk menyapa turis dengan membedakan panggilan mister, mrs, madam, mam, miss, dan lain-lain. Reaksi peserta dalam bertanya sangat efektif sekali dalam pembelajaran bahasa inggris. Peserta akan lebih muda mengingat materi apabila ia mengalami secara langsung materi yang ia pelajari. Simulasi membuat peta pantai untuk mengajarkan tentang giving direction juga diikuti dengan baik oleh 
peserta. Begitu juga dengan penggunaan gambar di media elektronik juga membuat proses pelatihan menarik.

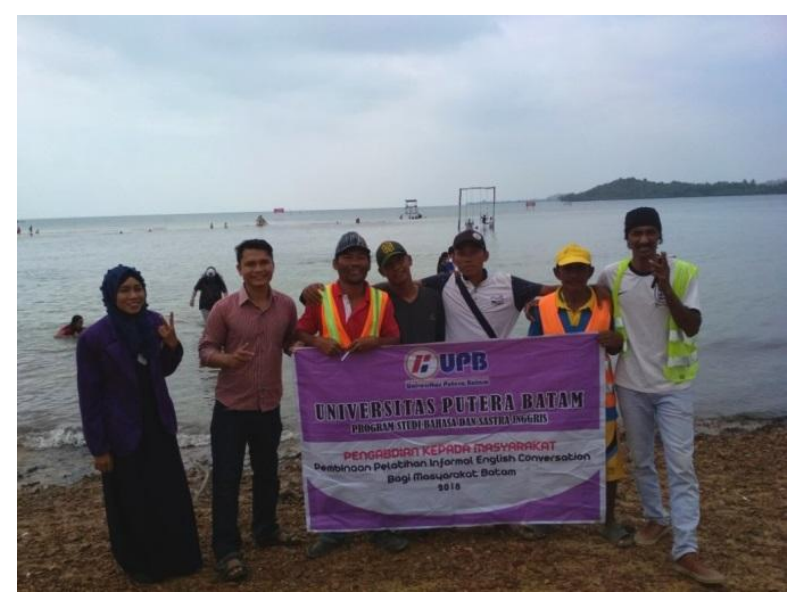

Gambar 5 Foto bersama tim pengabdi dengan peserta

Kunci dalam memahami english conversation skill adalah praktek secara langsung. Simulasi praktek conversation menunjukan bahwa adanya peningkatan kemampuan yang didapatkan oleh peserta pengabdian setelah pelatihan. Peserta telah mampu menyapa, memperkenalkan diri, memberikan arahan, dan menawarkan sesuatu dengan menggunakan bahasa inggris sederhana. Beberapa peserta juga berinisiatif untuk mendownload aplikasi kamus di handphone mereka untuk mempermudah merangkai kata dalam percakapan. Antusias peserta dalam mempelajari bahasa inggris ini hendaknya tidak berhenti sampai disini saja. Diharapkan ada pembinaan yang berkelanjutan agar kemampuan bahasa yang dmiliki oleh peserta semakin meningkat dan ilmu yang diajarkan tidak hilang begitu saja.

\section{KESIMPULAN}

Kemampuan berkomunikasi bahasa inggris yang baik sangat mendukung potensi wisata yang ada dikota Batam khususnya objek wisata pantai sitokok dikecamatan sibulang. Banyaknya wisatawan manca negara yang berkunjung menuntut SDM di objek wisata mampu berkomunikasi bahasa inggris yang baik. Pembinaan peningkatan english conversation skill bagi penjaga pantai merupakan solusi untuk mengatasi permasalahan komunikasi bahasa bagi SDM di objek wisata tersebut. Pembinaan yang dilakukan oleh tim pengabdi lebih difokuskan berkaitan dengan kebutuhan peserta pelatihan. Praktek conversation yang dilakukan juga berkaitan dengan aktifitas yang dilakukan oleh para peserta sendiri. Pelatihan bahasa di pantai ini juga baru pertama kali dilakukan. Peserta menyambut baik tim pengabdi karena solusi ini juga yang dibutuhkan untuk menyelesaikan permasalahan dalam berbahasa inggris.

Kunci untuk menguasa english conversation skill yang baik yaitu dengan mempraktekannya secara langsung. Pelatihan peningkatan bahasa ini juga menampilkan praktek secara kelompok dan individu antar peserta pelatihan. Dengan demikian peserta bisa memahami apa yang diajarkan tanpa menghafal teori yang diberikan. Peserta juga bisa mengembangkan bahasanya sendiri karena tim memberikan bekal kosakata berkaitan dengan lingkungan pantai. 
Pembinaan peningkatan english conversation penjaga pantai ini juga merupakan upaya untuk mendukung program wisata bahari Batam. Lokasi strategis Batam yang diapit dua Negara Malasyia dan Singapura menjadi pintu masuk untuk pariwisata mancanegara. Destinasi pantai setokok yang melewati jembatan barelang, salah satu icon kota Batam, memberikan dampak signifikan untuk menarik wisatawan berkunjung ke lokasi tersebut.

\section{SARAN}

Mengingat pentingnya kemampuan berkomunikasi bahasa inggris yang baik bagi SDM objek wisata pantai sitokok diharapkan ada proses pelatihan yang berkelanjutan dan kontinu. Fasilitasi pembinaan bahasa inggris juga sangat penting untuk mempertahankan kemampuan peserta yang telah diajarkan. Banyaknya wisatawan yang berkunjung membuktikan bahwa banyak peluang kemampuan berbahasa inggris yang bisa dimanfaatkan oleh masyarakat disekitar pantai sitokok. Bukan hanya kemampuan berkomunikasi, kemampuan menulis dan berbahasa juga penting diajarkan. Tim pengabdi selanjutnya bisa melanjutkan program dengan melakukan pelatihan promosi wisata dengan menggunakan bahasa inggris agar jumlah wisatawan asing yang berkunjung semakin meningkat. Pembinaan yang berkelanjutan berguna untuk mendukung majunya pariwisata dan dapat dirasakan oleh masyarakat sebagai pelaku dilapangan. Selain itu, keterlibatan tokoh masyarakat dan pejabat setempat juga dibutuhkan. Hal ini terkait dengan jumlah peserta yang mengikuti pembinaan. Dengan pelibatan tokoh masyarakat dan pejabat setempat, peserta yang mengikuti pembinaan akan semakin meningkat dan cakupan peserta pelatihan akan semakin luas.

\section{UCAPAN TERIMA KASIH}

Penulis mengucapkan terimakasih yang sebesar-besarnya kepada Universitas Putera Batam terutama Tim LPPM UPB atas bimbingan dan arahannya sehingga dapat menyelesaikan proses pengabdian ini. Selain itu juga, penulis mengucapkan terimakasih kepada mahasiswa dan masyarakat atau peserta pengabdian yang telah serius mengikuti pembinaan bahasa ini hingga akhir. Semoga ilmu yang didapatkan bisa bermanfaat dan diterapkan dalam pekerjaan.

\section{DAFTAR PUSTAKA}

Anwar Deeb, G. M. (2016). "Moments of infinite joy within a limited time": The concept of time in John Green's The Fault in our Stars, 7(8), 112-126. https://doi.org/10.5897//JEL2016.0927

BPS. (2017). DATA BPS; Jumlah kunjungan wisman ke Indonesia. Batam.

Fandeli, C. (2002). Perencanaan Kepariwisataan Alam. Bulaksumur, Yogyakarta: Fakultas Kehutanan dan Humaniora.

Flake, J. (2004). Cultural and Communication Studies: Sebuah Pengantar yang Paling Komprehensif. Yogyakarta.

Modjo, L. (2012). Membangun Desa Wisata. Jakarta: PT Grasindo Persada.

Suwanda, D. (2016). Walikota Rudia Targetkan 19 juta Wisman ke Batam. Warta Kepri. Retrieved from warta.kepri.co.id 
tom. (2017, April). Batam Dirancang Miniatur Indonesia dan Kota Wisata. Tribun News.com. Retrieved from http://batam.tribunnews.com/2012/04/16/batamdirancang-miniatur-indonesia-dan-kota-wisata 